\title{
Prevalence and Determinants of Complete Postnatal Care Service Utilization in Northern Shoa, Ethiopia
}

\author{
Mohammed Akibu $\mathbb{D}^{1},{ }^{1}$ Wintana Tsegaye, ${ }^{2}$ Tewodros Megersa, ${ }^{3}$ and Sodere Nurgi ${ }^{1}$ \\ ${ }^{1}$ Department of Midwifery, Institute of Medicine and Health Sciences, Debre Berhan University, Debre Berhan, Ethiopia \\ ${ }^{2}$ Concordia University, Montreal, Quebec, Canada \\ ${ }^{3}$ Obstetrics Unit, Gandhi Maternal Specialized Hospital, Addis Ababa, Ethiopia
}

Correspondence should be addressed to Mohammed Akibu; mahammedakibu@gmail.com

Received 4 March 2018; Revised 19 June 2018; Accepted 16 July 2018; Published 14 August 2018

Academic Editor: Fabio Facchinetti

Copyright (C) 2018 Mohammed Akibu et al. This is an open access article distributed under the Creative Commons Attribution License, which permits unrestricted use, distribution, and reproduction in any medium, provided the original work is properly cited.

\begin{abstract}
Background. Postnatal period presents the highest risk of death for mothers and newborns. Although progress has been made in expanding the coverage for most of maternal health services, national prevalence of postnatal care service utilization in Ethiopia is still extremely limited. Hence, this study aims to determine the prevalence and factors associated with complete postnatal care service utilization in Northern Shoa, Ethiopia. Methods. Community based cross-sectional survey was conducted between November 2016 and February 2017. A total of 510 mothers were included in the study using multistage sampling technique. The data were collected through face-to-face interview. Bivariate and multivariate logistic regression models were fitted to identify factors associated with complete postnatal care utilization at $\mathrm{p}$ value of $<0.05$. SPSS version 20 was used to analyze the data. Results. The prevalence of complete postnatal care utilization was found to be $28.4 \%$ in the study area. Mode of delivery $(\mathrm{AOR}=5.7,95 \% \mathrm{CI}=3.9$, 19), number of children ( $A O R=2.595 \% \mathrm{CI}, 1.4,14.2)$, and level of education (AOR=3.2 95\% CI, 1.1, 9.2) were the factors statistically associated with complete postnatal service uptake. Being healthy was the major (48.8\%) reason mentioned for not complying with the recommended three postnatal visits. Conclusion. The prevalence of complete postnatal care service in the study area was found to be low, and it is far less than the targeted zonal and regional plan. Reinforcing the existing policies and strategies to increase women level of awareness about postnatal care and intensive counseling during antenatal care and delivery are the recommendations based upon the current finding.
\end{abstract}

\section{Background}

The postnatal period (PNP) is the time beginning immediately following the delivery of the placenta and extending through the six weeks (42 days) of birth. This period represents a critical phase in determining the health and survival of the mother and her newborn [1]. The wellbeing and chance of staying free of morbidity or mortality are much dependent upon the care given during pregnancy, delivery, and most importantly after delivery, the time when many maternal and neonatal deaths take place. Therefore, lack of care during postnatal period may end up in death or morbidity as well as missed opportunities to various healthy behaviors benefiting the mother and her newborn $[2,3]$

For both newborns and mothers, the highest risk of death occurs at delivery, followed by the first hours and days after childbirth. It has been shown that more than two-thirds of newborn deaths would occur by the end of the first week after delivery, with up to one-half of all newborn deaths occurring in the first 24 hours. Similarly, approximately two-thirds of all maternal deaths occur in the postnatal period $[4,5]$.

Although some countries have made a dramatic progress, half of the maternal deaths in the world still take place in Sub-Saharan Africa where little or no progress has been made. Even though there is no single, simple, straightforward intervention that will significantly decrease maternal mortality, several studies have shown that majority of these maternal and neonatal problems could be reduced if women receive appropriate postnatal care [6-9]. In spite of proven benefits of postnatal care on maternal and neonatal health, most newborns and mothers do not receive this service 
from a skilled healthcare provider during the first few days after delivery; thus, this is the most neglected period for the provision of quality care. Similarly, rates of provision of skilled care are much lower during postnatal period when compared to rates before and during childbirth $[3,10]$ Likewise, the coverage of postnatal care (PNC) in Ethiopia remains alarmingly limited with only $7 \%$ increment over the last one and half decade $[11,12]$. Hence, this study aimed at providing a contemporary evidence about the level of PNC coverage and various determinant factors in Northern Shoa, Ethiopia.

\section{Methods}

2.1. Study Design and Population. Community based crosssectional study was conducted from November 2016 to February 2017 with 520 mothers who gave birth within the last ten months preceding the survey. The study was conducted at Debre Berhan town, the capital city of Northern Shoa zone of Amhara regional state located about 130 kilometers to the North East of Addis Ababa (the capital of Ethiopia). Debre Berhan town contains nine urban and five rural kebeles according to administrative classification with estimated population size of 84,944 . More than half 43,696 (51.4\%) of the population in the town are represented by females. Of total females, 26,876 of them are found within reproductive age (15-49) group.

2.2. Inclusion and Exclusion Criteria. All women who have given birth within the last ten months preceding the survey were included. Women admitted for much of postnatal periods, those who gave birth greater than ten months ago, and women with still births were excluded from the study.

2.3. Sample Size and Sampling Procedure. The sample size for the current study was calculated using single population proportion formula with the assumption of $95 \%$ confidence level, $20.2 \%$ prevalence of postnatal care utilization [13], 5\% marginal error, and design effect of 2 . The final sample size (520) was obtained after 5\% adjustment for nonresponse rate. The sample size was distributed proportionally for each selected kebeles (the smallest administrative unit in Ethiopia). Finally, systematic random sampling with $\mathrm{k}^{\text {th }}$ value of five was used to obtain the study subjects in each selected kebele.

2.4. Variables and Measurements. The outcome variable was complete postnatal care service utilization which refers to postnatal care service uptake within 24 hours of delivery, the first 3-7 days after delivery, and 7-14th days subsequently. Women who have received the service during all three periods were considered to have complete utilization. The independent variables comprised various sociodemographic (age, educational status, income, and marital status), obstetrics (parity, mode of delivery, ANC use, course of pregnancy, and plan for the current pregnancy), and other health service related characteristics (autonomy, distance from health facility).
The outcome variable was measured by asking the practice and timing of postnatal care visit with three possible responses (i.e., (1) only received postnatal care once after delivery, (2) received twice within the recommended postnatal schedule (successive or interrupted), and (3) received thrice subsequent postnatal care within the recommended time frame). This self-reported visit was cross-confirmed by reviewing postnatal registration records. Finally, the outcome variable was dichotomized as 1: complete PNC utilization and 0 : sporadic PNC utilization.

2.5. Data Collection and Quality Control. The data were collected using a structured questionnaire via a face-to-face interview at the participant's home. The questionnaire was first prepared in English and then translated into local language (Amharic) and back to English to ensure consistency. The pretest was done on $5 \%$ of the total sample size and a necessary adjustment was made. Six midwives and two nurses who are fluent in speaking the local language were involved in the data collection. Two-day training was given to the data collectors and supervisors.

\subsection{Operational Definition}

Complete Postnatal Visit. It is for mothers who have stayed in the hospital for 24 hours after delivery and returned for checkup between 3-7 days and 7-14 days subsequently.

Seclusion. It is a cultural/social practice that forbids mothers from going out and/or joining peoples for 40 days starting from the day of delivery.

2.7. Data Analysis. The data were described using frequency and/or cross-tabulation for categorical variables and mean (standard deviation (SD)) for continuous variables. Binary and multiple logistic regression tests were carried out to identify associated factors at $\mathrm{p}$ value threshold $<0.05$. The data were coded, cleaned, and entered using EPI-INFO version 7 and analyzed with SPSS version 20. The result was reported strictly following Strengthening the Reporting of Observational Studies in Epidemiology (STROBE) Statement (Supplementary File (available here)).

\section{Results}

3.1. Sociodemographic Characteristics. A total of 510 mothers participated in the study making a response rate of $98 \%$. Nearly one-third $(31.8 \%)$ of respondents were found within the age group of 25-29. Majority of the participants were from Amhara (79.4\%) ethic group and orthodox $(72.5 \%)$ religious background. One-quarter (26.9\%) of the mothers attended at least secondary level education and a significant number of women (21.4\%) had no any graded education but can read and write (Table 1$)$.

3.2. Obstetrics Characteristics. More than half (56.7\%) of participants were low multiparous (with children between two and four), whereas nearly third of (29.2\%) mothers were primiparous. Some (11.6\%) of the mothers reported 
TABLE 1: Sociodemographic characteristics of women who gave birth within the last ten months preceding the survey, Northern Shoa, Ethiopia 2017.

\begin{tabular}{|c|c|c|}
\hline Sociodemographic characteristics & Frequency (n) & Percent (\%) \\
\hline \multicolumn{3}{|l|}{ Age } \\
\hline $15-19$ & 44 & 8.6 \\
\hline $20-24$ & 150 & 29.4 \\
\hline $25-29$ & 162 & 31.8 \\
\hline $30-34$ & 94 & 18.4 \\
\hline 35 and above & 60 & 11.8 \\
\hline \multicolumn{3}{|l|}{ Marital Status } \\
\hline Unmarried & 30 & 5.9 \\
\hline Married & 456 & 89.4 \\
\hline Divorced & 24 & 4.7 \\
\hline \multicolumn{3}{|l|}{ Ethnicity } \\
\hline Amhara & 405 & 79.4 \\
\hline Tigree & 37 & 7.3 \\
\hline Oromo & 39 & 7.6 \\
\hline Gurage & 26 & 5.1 \\
\hline Others $^{\mathrm{a}}$ & 3 & .6 \\
\hline \multicolumn{3}{|l|}{ Religion } \\
\hline Orthodox & 370 & 72.5 \\
\hline Muslim & 86 & 16.9 \\
\hline Protestant & 41 & 8.0 \\
\hline Catholic & 9 & 1.8 \\
\hline Others $^{\mathrm{b}}$ & 4 & .8 \\
\hline \multicolumn{3}{|l|}{ Educational Status } \\
\hline Illiterate & 26 & 5.1 \\
\hline Read and write & 109 & 21.4 \\
\hline Primary Education & 125 & 24.5 \\
\hline Secondary Education & 137 & 26.9 \\
\hline Higher Education & 113 & 22.2 \\
\hline \multicolumn{3}{|l|}{ Husband Education } \\
\hline Illiterate & 54 & 10.6 \\
\hline Read and write & 72 & 14.1 \\
\hline Primary Education & 111 & 21.7 \\
\hline Secondary Education & 98 & 19.3 \\
\hline Higher Education & 175 & 34.3 \\
\hline \multicolumn{3}{|l|}{ Household Income } \\
\hline$<\$ 25$ & 248 & 48.6 \\
\hline$\$ 26-\$ 99$ & 173 & 33.9 \\
\hline$\$ 100$ or more & 89 & 17.5 \\
\hline \multicolumn{3}{|l|}{ Mother occupation } \\
\hline House Wife & 252 & 49.4 \\
\hline Self-Employee & 100 & 19.6 \\
\hline Government Employee & 114 & 22.4 \\
\hline Maid servant & 32 & 6.3 \\
\hline Student & 12 & 2.4 \\
\hline
\end{tabular}

${ }^{\mathrm{a}}$ Afar and Wolayita; ${ }^{\mathrm{b}}$ Bhai and apostolic.

that the most recent pregnancy was complicated and most $(39 \%)$ of this problem was attributed to premature rupture of membrane. Cesarean section accounted for $18 \%$ of these deliveries and $3.9 \%$ of babies born were twins. More than half $(53.7 \%)$ of participants received the recommended four or more antenatal care service (ANC) (Table 2).

3.3. Postnatal Care Service. Only $28.4 \%$ of participants received the recommended three postnatal care visits within six weeks of delivery. Among mothers who have visited antenatal care clinic, the majority $(58.4 \%)$ of these women did not receive counseling about postnatal care. Similarly, only $18.4 \%$ of these women initially had information about postnatal care service from different sources. About twothirds $(76.3 \%)$ of mothers suggested that there was a social and cultural norm called "Seclusion" which forbids them from coming out of home after delivery. Most importantly almost half $(49.1 \%)$ of these women respond that this event was more important and valuable than any outdoor visit (Table 3).

3.4. Factors Associated with Complete Postnatal Care Utilization. In multivariate logistic regression model, mothers who have given birth through cesarean section were 5.7 $[\mathrm{AOR}=5.795 \% \mathrm{CI}=3.9-19]$ times more likely to receive complete postnatal care service than those who delivered through spontaneous vaginal delivery. Similarly, mothers having one child (primiparous) were 4.5 more likely to have full postnatal care $[\mathrm{AOR}=2.595 \% \mathrm{CI} 1.4-14.2]$ than multiparous women. Level of education $[\mathrm{AOR}=3.295 \% \mathrm{CI}$, 1.1, 9.2] was another factor which is statistically significant with complete postnatal care utilization (Table 4).

\section{Discussion}

The current study revealed that only 145 (28.4\%) of mothers have received complete postnatal care as per the standard recommendation. This finding was slightly higher compared to the reports from other studies $[13,14]$. This discrepancy may be attributed to the time gap difference as there would be an improvement on access to healthcare and awareness about the service through time. However, a study conducted in Addis Ababa city administrative by Senait Berhanu and Berhanu wordofa indicated that the postnatal care prevalence was twice of this report (65.6\%) [15]. This disparity might be explained by the sociodemographic variation between the study participants such as educational level and living standard as well as nature of the study area including better access to healthcare.

The current study has shown that mothers who attended higher education were three times more likely to receive complete postnatal care service than illiterate women $[\mathrm{AOR}=3.2$ $95 \%$ CI, 1.1, 9.2]. This finding was in agreement with results from Dembecha district, North west Ethiopia, Nepal, Nigeria, and one more study in Ethiopia [16-19]. This could be explained by the notion that education is a key factor in empowering maternal decision making towards healthcare service, increasing awareness of basic health services, and being informed about health risks, with all of these eventually leading to the improved health seeking behavior. 
TABLE 2: Distribution of obstetrics history of women who gave birth within the last ten months preceding the survey, in Northern Shoa, Ethiopia 2017.

\begin{tabular}{|c|c|c|}
\hline Obstetrics characteristics & Frequency (n) & Percent (\%) \\
\hline \multicolumn{3}{|l|}{ Number of children alive } \\
\hline One & 149 & 29.2 \\
\hline Two - four & 290 & 56.7 \\
\hline Five and above & 71 & 13.9 \\
\hline $\mathrm{ANC}$ in recent pregnancy & 454 & 89 \\
\hline Yes & 56 & 11 \\
\hline \multicolumn{3}{|l|}{ No } \\
\hline \multicolumn{3}{|l|}{ Number of visits } \\
\hline One & 38 & 8.4 \\
\hline Two & 54 & 11.9 \\
\hline Three & 88 & 19.4 \\
\hline Four and above & 274 & 60.4 \\
\hline \multicolumn{3}{|l|}{ Course of Pregnancy } \\
\hline Complicated & 59 & 11.6 \\
\hline Uncomplicated & 451 & 88.4 \\
\hline \multicolumn{3}{|l|}{ Type of conditions faced } \\
\hline Hypertensive disorders & 10 & 16.9 \\
\hline PROM & 23 & 39.0 \\
\hline Post Term & 14 & 23.7 \\
\hline Anemia & 7 & 11.9 \\
\hline Bleeding during pregnancy & 5 & 8.5 \\
\hline \multicolumn{3}{|l|}{ Mode of delivery } \\
\hline SVD & 356 & 69.8 \\
\hline SVD assisted with Instrument & 62 & 12.2 \\
\hline Cesarean section & 92 & 18.0 \\
\hline \multicolumn{3}{|l|}{ Number of babies born } \\
\hline Single & 490 & 96.1 \\
\hline Twins & 20 & 3.9 \\
\hline \multicolumn{3}{|c|}{ Autonomy on Heath care seeking } \\
\hline It's up to me to decide & 424 & 83.1 \\
\hline It's not only me & 86 & 16.9 \\
\hline
\end{tabular}

*ANC: antenatal care; $*$ SVD: spontaneous vaginal delivery; * PROM: premature rupture of membranes.

Cesarean section delivery resulted in increased odds of having complete postnatal service. This finding has also been supported by different studies from Ethiopia and Tanzania [20-22]. This could be because mothers who had operative delivery are tending to have greater perceived susceptibility to a wide range of postoperative complications; therefore, frequent return to the health institution would be the strategy to minimize these perceived risks. Primiparity was another obstetrics determinant for full postnatal care service attendance. Studies in Ethiopia and Nepal have shown consistent finding $[19,20,23]$. This might be justified by the fact that first time mothers are usually dependent upon the support of health professionals and their family on infant care and feeding practice. Similarly, they would be very curious about the health of their newborn baby; thus, these needs might be satisfied through frequent contact with health professionals.

\section{Limitation of the Study}

The result of this study must be interpreted cautiously considering the following inevitable limitations. Though the study has included mothers who gave birth in the last ten months, there might be a possibility of some recall bias. Causality cannot be inferred due to the cross-sectional nature of the study. Moreover, the external validity of the finding might be limited. However, it is the first study which tried to assess the level of complete postnatal care visit in the study area.

\section{Conclusion}

The coverage of full postnatal care service in the study was found to be lower than the targeted zonal and regional plan. Maternal educational status, parity, and mode of delivery 
TABLE 3: Coverage of postnatal care services and related information's among women who gave birth in the last ten months preceding this survey, Northern Shoa, Ethiopia, 2017.

\begin{tabular}{|c|c|c|}
\hline Variables & Frequency $(\mathbf{n})$ & Percent (\%) \\
\hline \multicolumn{3}{|l|}{ Postnatal care utilization } \\
\hline Complete PNC ( 3 or more visits) & 145 & 28.4 \\
\hline Sporadic PNC ( 2 or less PNC) & 365 & 71.6 \\
\hline \multicolumn{3}{|c|}{ Reason for not complying with PNC recommendation } \\
\hline I didn't know about its importance & 124 & 33.9 \\
\hline It's a waste of time once we get birth & 39 & 10.7 \\
\hline I waited long time to get the service & 57 & 15.6 \\
\hline Baby and I were completely healthy & 178 & 48.8 \\
\hline Social reasons & 84 & 23 \\
\hline \multicolumn{3}{|l|}{ Counseling about PNC } \\
\hline Yes & 189 & 41.6 \\
\hline No & 265 & 58.4 \\
\hline \multicolumn{3}{|l|}{ Previous Information about PNC } \\
\hline Had information & 94 & 18.4 \\
\hline Never had information & 416 & 81.6 \\
\hline \multicolumn{3}{|l|}{ Source of Information } \\
\hline Media & 19 & 20.2 \\
\hline Magazines or other reading materials & 30 & 31.9 \\
\hline Health extension workers & 57 & 60.6 \\
\hline Friends & 13 & 13.8 \\
\hline \multicolumn{3}{|l|}{ Postdelivery seclusion } \\
\hline Yes & 389 & 76.3 \\
\hline No & 121 & 23.7 \\
\hline \multicolumn{3}{|l|}{ Postnatal care vs seclusion } \\
\hline It's more important than any clinic visit & 191 & 49.1 \\
\hline No difference to me & 103 & 26.5 \\
\hline No, the visit would be more important & 95 & 24.4 \\
\hline
\end{tabular}

* PNC: postnatal care.

were factors significantly associated with postnatal acre service utilization. Reinforcing the existing policies and strategies to increase mother's level of awareness about postnatal care, intensive counseling during antenatal and delivery, and scheduling mothers based on the national postnatal care follow-up protocol to increase postnatal care service utilization were recommended.

\section{Data Availability}

The data used to support the findings of this study are available from the corresponding author upon request.

\section{Ethical Approval}

Ethical approval was obtained from the Institutional Review Board (IRB) of Debre Berhan University, Institute of Medicine and Health Science.

\section{Consent}

Both written and verbal consent were taken from the study subjects after explaining the purpose and procedures of the study. Information obtained was kept confidential.

\section{Conflicts of Interest}

The authors declare that they have no conflicts of interest.

\section{Authors' Contributions}

Mohammed Akibu conceived and designed the study. Mohammed Akibu, Tewodros Megersa, and Sodere Nurgi supervised the data collection and prepared the manuscript. Mohammed Akibu and Wintana Tsegaye performed analysis and interpretation of the data. All authors read and approved the final manuscript.

\section{Acknowledgments}

The authors would like to pass their gratitude to the University of Debre Berhan for its ethical approval. Their appreciation also extends to all mothers who took part in the study.

\section{Supplementary Materials}

Supplementary File. Strengthen the report of observational studies in Epidemiology (STROBE) checklist. (Supplementary Materials) 
TABLE 4: Bivariate and multivariate analysis of factors associated with complete postnatal care service utilization, Northern Shoa, Ethiopia, 2017.

\begin{tabular}{|c|c|c|c|c|c|}
\hline \multirow{2}{*}{ Variables } & & \multicolumn{2}{|c|}{ PNC } & \multirow{2}{*}{ Crude OR $(95 \%, C I)$} & \multirow{2}{*}{ Adjusted OR $(95 \%, C I)$} \\
\hline & & Complete & Sporadic & & \\
\hline \multirow{5}{*}{ Husband education } & Illiterate & 15 & 39 & 1 & 1 \\
\hline & Read and Write & 15 & 57 & $.684(.300,1.559)$ & $.431(.151,1.226)$ \\
\hline & Primary education & 16 & 95 & $.438(.196, .972$ & $.254(.091, .706)$ \\
\hline & Secondary education & 26 & 72 & $.939(.446,1.98)$ & $.807(.316,2.061)$ \\
\hline & Higher education & 73 & 102 & $1.861(1.25,3.62) *$ & $1.253(.531,2.956)$ \\
\hline \multirow{5}{*}{ Maternal Education } & Illiterate & 2 & 24 & 1 & 1 \\
\hline & Read and write & 27 & 82 & $3.9(.876,17.83)$ & $3.1(.597,16.9)$ \\
\hline & Primary Education & 30 & 95 & $3.7(.846,16.9)$ & $2.5(.476,13.1)$ \\
\hline & Secondary Education & 35 & 102 & $4.1(.925,18.32)$ & $2.02(.387,10.5)$ \\
\hline & Higher education & 51 & 62 & $6.8(2.226,14.34)$ & $3.2(1.19,9.2) *$ \\
\hline \multirow{3}{*}{ Parity } & Primiparous & 58 & 91 & $2.08(1.2,7.8)$ & $2.5(1.42,14.2) *$ \\
\hline & Multiparous & 88 & 202 & $1.7(.692,4.37)$ & $1.76(.575,5.39)$ \\
\hline & Grande multiparous & 24 & 47 & 1 & 1 \\
\hline \multirow{2}{*}{ Information about PNC } & Had information & 32 & 62 & $1.34(1.08,2.23) *$ & $1.98(.553,3.74)$ \\
\hline & Had no information & 113 & 303 & 1 & 1 \\
\hline \multirow{2}{*}{ Autonomy on health care } & Self-decision & 117 & 307 & $1.79(1.479,6.30) *$ & $1.27(.362,2.261)$ \\
\hline & Collaborative decision & 28 & 58 & 1 & 1 \\
\hline \multirow{3}{*}{ Mode of delivery } & SVD & 88 & 268 & 1 & 1 \\
\hline & SVD with instrumentation & 19 & 43 & $3.27(.927,4.3)$ & $4.27(.82,6.2)$ \\
\hline & Cesarean section & 38 & 54 & $2.35(1.45,3.81) *$ & $5.7(3.96,18.3) *$ \\
\hline \multirow{2}{*}{ Number of babies born } & Singleton & 140 & 350 & 1 & 1 \\
\hline & Twins & 5 & 15 & $.833(.297,2.336)$ & $1.025(.295,3.558)$ \\
\hline \multirow{2}{*}{ Counseling on PNC } & Received & 48 & 141 & $.709(.467,1.075)$ & $.737(.446,1.217)$ \\
\hline & Not received & 86 & 179 & 1 & 1 \\
\hline
\end{tabular}

* Statistically significant variable; 1 reference category; COR: crude odds ratio; AOR: adjusted odds ratio.

\section{References}

[1] X. F. Li, J. A. Fortney, M. Kotelchuck, and L. H. Glover, “The postpartum period: The key to maternal mortality," International Journal of Gynecology and Obstetrics, vol. 54, no. 1, pp. 1-10, 1996.

[2] J. E. Lawn, S. Cousens, and J. Zupan, “4 Million neonatal deaths: when? Where? Why?” The Lancet, vol. 365, no. 9462, pp. 891900, 2005.

[3] The Partnership for Maternal Newborn and Child Health. Opportunities for Africa's newborns: Practical data, policy and programmatic support for newborn care in Africa. world health organization 2006 (cited 2017 February); Available from: http://www.who.int/pmnch/knowledge/publications/africanewborns/en/.

[4] Joy E. Lawn analysis based on 38 DHS datasets (2000 to 2004) with 9,022 neonatal deaths, using MEASURE DHS STAT compiler (https://dhsprogram.com/). Used in: Save the ChildrenU.S., State of the World/s Mothers 2006 (Washington, DC: Save the Children-U.S., 2006).

[5] R. Carine and J. G. Wendy, "Maternal mortality: who, when, where, and why," The Lancet, vol. 368, no. 9542, pp. 1189-1200, 2006.

[6] World Health Organization. WHO technical consultation on postpartum and postnatal care. 2010 (cited 2017 March);
Available from: http://www.who.int/maternal_child_adolescent/ documents/WHO_MPS_10_03/en/.

[7] P. K. Singh, C. Kumar, R. K. Rai, and L. Singh, "Factors associated with maternal healthcare services utilization in nine high focus states in India: A multilevel analysis based on 14385 communities in 292 districts," Health Policy and Planning, vol. 29, no. 5, pp. 542-559, 2014.

[8] R. Pattinson, K. Kerber, E. Buchmann et al., "Stillbirths: How can health systems deliver for mothers and babies?" The Lancet, vol. 377, no. 9777, pp. 1610-1623, 2011.

[9] A. Blank, H. Prytherch, J. Kaltschmidt et al., "'Quality of prenatal and maternal care: bridging the know-do gap' (QUALMAT study): an electronic clinical decision support system for rural Sub-Saharan Africa," BMC Medical Informatics and Decision Making, vol. 13, article 44, 2013.

[10] World Health Organization. WHO recommendations on postnatal care of the mother and newborn. 2013 (cited 2017 May); Available from: http://www.who.int/maternal_child_adolescent/ documents/postnatal-care-recommendations/en/.

[11] Central Statistical Authority [Ethiopia] and ORC Macro. 2001. Ethiopia Demographic and Health Survey 2000. Addis Ababa, Ethiopia and Calverton, Maryland, USA: Central Statistical Authority and ORC Macro.

[12] Central Statistical Agency (CSA) [Ethiopia] and ICF. 2016. Ethiopia Demographic and Health Survey 2016: Key Indicators 
Report. Addis Ababa, Ethiopia, and Rockville, Maryland, USA. CSA and ICF.

[13] Y. Gebeyehu Workineh, "Factors Affecting Utilization of Postnatal Care Service in Amhara Region, Jabitena District, Ethiopia," Science Journal of Public Health, vol. 2, no. 3, pp. 169176, 2014.

[14] H. Alemayeh, H. Assefa, and Y. Adama, "Prevalence and Factors Associated with Post Natal Care Utilization in Abi-Adi Town, Tigray, Ethiopia: A Cross Sectional Study," International Journal of Pharmaceutical and Biological Sciences Fundamentals, vol. 8, no. 1, 2014.

[15] S. Berhanu, Y. Asefa, and B. W. Giru, "Prevalence of Postnatal Care Utilization and Associated Factors among Women Who Gave Birth and Attending Immunization Clinic in Selected Government Health Centers in Addis Ababa, Ethiopia," Journal of Health, Medicine and Nursing, vol. 26, 2016.

[16] M. Ayana Hordofa, S. S. Almaw, M. G. Berhanu, and H. B. Lemiso, "Postnatal Care Service Utilization and Associated Factors Among Women in Dembecha District, Northwest Ethiopia," Science Journal of Public Health, vol. 3, no. 5, pp. 686692, 2015.

[17] K. Vishnu, M. Adhikari, R. Karkee, and T. Gavidia, "Factors associated with the utilisation of postnatal care services among the mothers of Nepal: Analysis of Nepal Demographic and Health Survey 2011," BMC Women's Health, vol. 14, no. 19, 2014.

[18] O. D. Somefun and L. Ibisomi, "Determinants of postnatal care non-utilization among women in Nigeria," BMC Research Notes, vol. 9, no. 1, article no. 21, 2016.

[19] S. M. Tarekegn, L. S. Lieberman, and V. Giedraitis, "Determinants of maternal health service utilization in Ethiopia: analysis of the 2011 Ethiopian Demographic and Health Survey," BMC Pregnancy and Childbirth, vol. 14, no. 1, article 161, 2014.

[20] K. Mehari and E. Wencheko, "Factors affecting maternal health care services utilization in rural Ethiopia: a study based on the 2011 EDHS data," Ethiopian Journal of Health Development, vol. 27, no. 1, pp. 16-24, 2013.

[21] M. A. Limenih, Z. M. Endale, and B. A. Dachew, "Postnatal Care Service Utilization and Associated Factors among Women Who Gave Birth in the Last 12 Months prior to the Study in Debre Markos Town, Northwestern Ethiopia: A Community-Based Cross-Sectional Study," International Journal of Reproductive Medicine, vol. 2016, Article ID 7095352, 7 pages, 2016.

[22] D. Mohan, S. Gupta, A. LeFevre, E. Bazant, J. Killewo, and A. H. Baqui, "Determinants of postnatal care use at health facilities in rural Tanzania: Multilevel analysis of a household survey," BMC Pregnancy and Childbirth, vol. 15, no. 282, 2015.

[23] S. Dhakal, G. N. Chapman, P. P. Simkhada, E. R. van Teijlingen, J. Stephens, and A. E. Raja, "Utilisation of postnatal care among rural women in Nepal," BMC Pregnancy and Childbirth, vol. 7, no. 1, p. 19, 2007. 


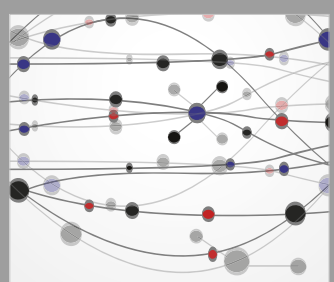

The Scientific World Journal
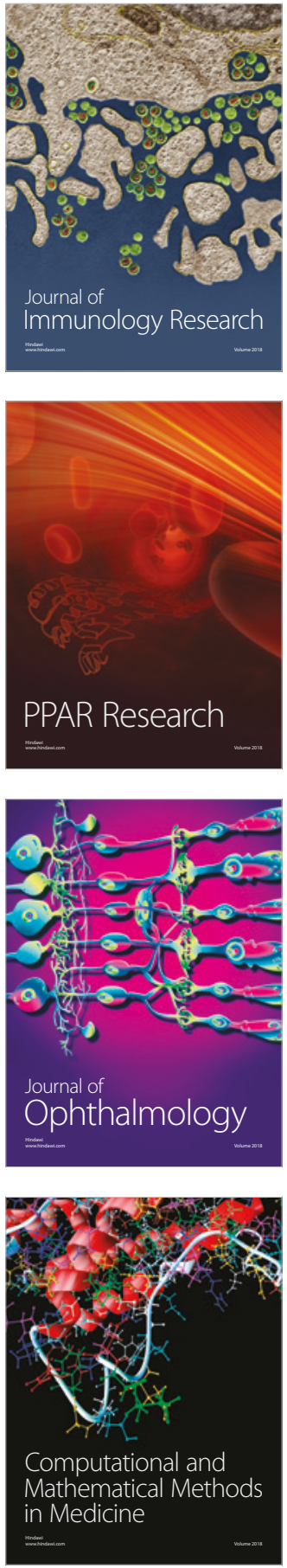

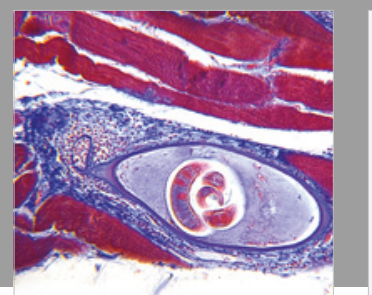

Gastroenterology Research and Practice

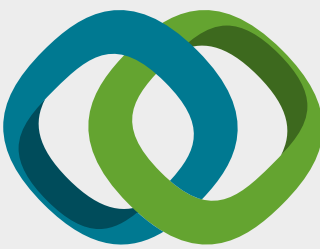

\section{Hindawi}

Submit your manuscripts at

www.hindawi.com
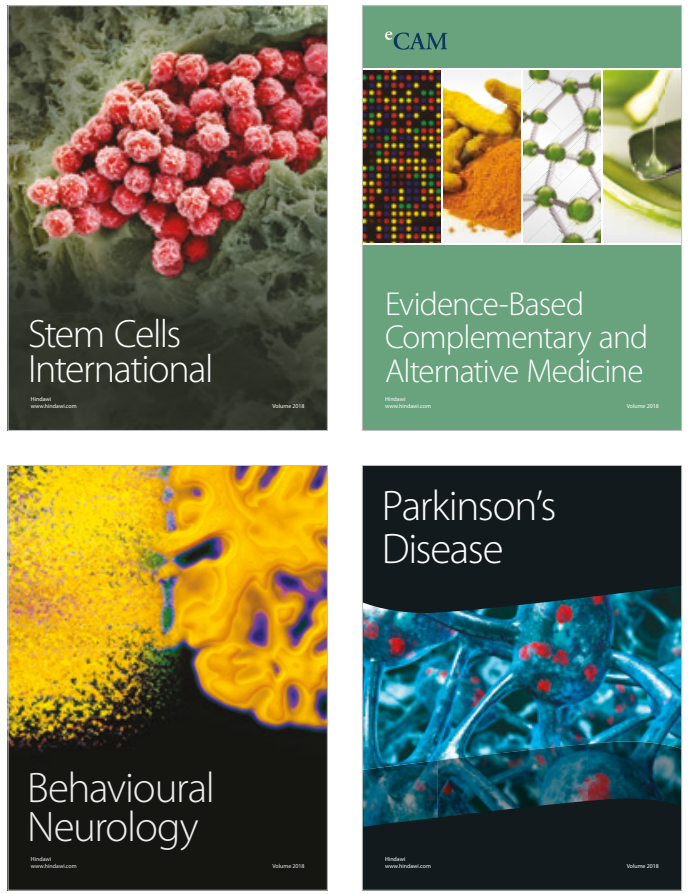

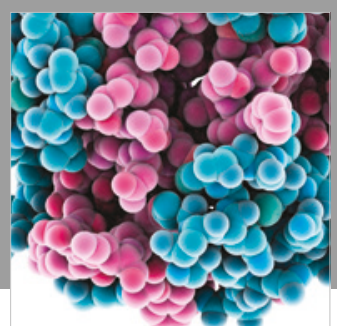

ournal of

Diabetes Research

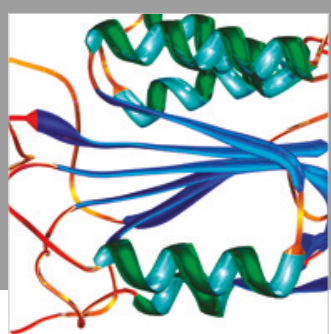

Disease Markers
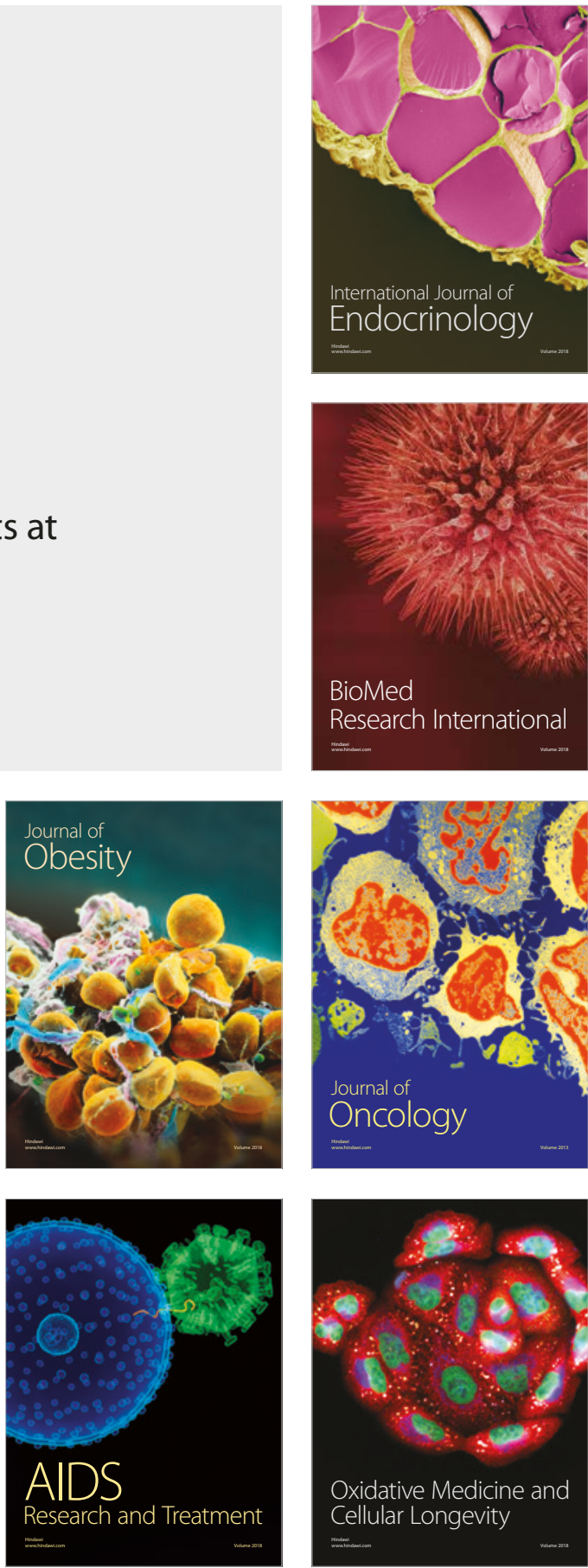